\title{
PENGARUH MEDIA SEMPOA TERHADAP KEMAMPUAN OPERASI HITUNG PENGURANGAN SISWA KELAS II MI
}

\author{
${ }^{1)}$ Akhmad Aji Pradana, Prodi PGMI, Fakultas Tarbiyah, IAINU Tuban, \\ email : ajipradana@stitmatuban.ac.id \\ ${ }^{2)}$ Jazilatul Ummah, Prodi PGMI, Fakultas Tarbiyah, IAINU Tuban, \\ email : jazilpgmiainutuban@gmail.com
}

\begin{abstract}
Many students don't like math. This dislike makes students not very familiar with subtraction calculation operations, thus making the students' ability to calculate subtraction operations is still low in completing subtraction count operations. Based on the background of the problem, this study is expected to provide answers to the formulation of the problem "How is the influence of the abacus media on the ability to calculate the reduction of second grade students at MI Islamiyah Mulyoagung Singgahan Tuban 2019/2020?". Based on the formulation of the problem, this study aims "To describe the effect of abacus media on the ability to count reduction operations in grade II students at MI Islamiyah Mulyoagung Singgahan Tuban 2019/2020".

This research uses Quasi Experiment method with quantitative approach through independent sample $t$ test analysis technique. Data collection methods in this study used observation, tests and documentation. The data obtained were analyzed using descriptive analysis then clarified with tables and graphs. The subject of this research is MI Islamiyah Mulyoagung Singgahan Tuban with samples according to the population of 34 students and the sampling technique used was random sampling technique.

From the results of the study it can be concluded that tcount $=3.882$ and ttable $=1.693$. This means that tcount> ttable so that it can be concluded that there is an influence of the use of abacus media on the ability to calculate grade II student reduction operations at MI Islamiyah Mulyoagung. Increased ability to count reduction operations is influenced by the use of abacus media. This is evidenced from the average value of pretest and posttest. Before the experimental group was given a tretment the average pretest value obtained was 69 in the medium category, and after being given a treatment the posttest average value was 81.76 in the high category. While the control group obtained an average pretest value of 68 in the moderate category and because the control group was not given an average treatment of the posttest obtained by 68.82 in the moderate category.
\end{abstract}

Keywords: Ability, Subtraction Operations, Abacus Media.

\section{Pendahuluan}

Matematika adalah pelajaran yang cenderung kurang diminati peserta didik, kebanyakan dari mereka menganggap bahwa matematika merupakan pelajaran yang sangat sulit dan membosankan, sehingga pelajaran ini tidak begitu digemari dibandingkan pelajaran lainnya, sama halnya di lembaga pendidikan Madrasah Ibtidaiyah Islamiyah Mulyoagung Sing gahan Tuban. Madrasah Ibtidaiyah adalah lembaga pendidikan yang kedudukannya setara dengan 
Sekolah Dasar pada umumnya. Peran lembaga pendidikan bukan hanya sekedar transfer of knowledge antara pendidik dan peserta didik yang berlangsung dalam suasana edukatif, tetapi ada kemampuan yang harus dikembangkan dalam setiap proses pembelajaran peserta didik di sekolah. Kemampuan tersebut berupa kemampun yang membantu proses pembelajaran menjadi lebih baik. Dalam meningkatkan kemampuan peserta didik perlu adanya media sebagai penyambung materi yang digunakan dengan hasil kemampuan yang harus dikuasai peserta didik. Seperti halnya dalam mempelajari matematika yang diharuskan memiliki kemampuan berhitung, dimana kemampuan berhitung ini sebagai kemampuan dasar untuk mempelajari ilmu matematika tersebut.

Melihat permasalahan tersebut diduga perlu adanya media pembelajaran yang digunakan untuk membantu meningkatkan kemampuan berhitung peserta didik kelas II MI Islamiyah Mulyoagung. Salah satu media hitung yang bisa digunakan adalah sempoa. Sempoa adalah alat bantu untuk menghitung yang terbuat dari rangka kayu dengan sederetan poros berisi manikmanik yang dapat digeser-geserkan. Sempoa digunakan untuk melakukan operasi aritmatika seperti penjumlahan, pengurangan, perkalian, dan pembagian (Kudlori dan Hidayat, 2014:15).

Dari latar belakang di atas maka rumusan masalah dalam penelitian ini adalah "Bagaimana pengaruh media sempoa terhadap kemampuan operasi hitung pengurangan siswa kelas II di MI Islamiyah Mulyoagung Singgahan Tuban tahun pelajaran 2019/2020”. Berdasarkan permasalahan yang telah dirumuskan sebelumnya, maka penelitian ini bertujuan untuk mendeskripsikan pengaruh media sempoa terhadap kemampuan operasi hitung pengurangan siswa kelas II di MI Islamiyah Mulyoagung Singgahan Tuban tahun pelajaran 2019/2020.

\section{Kajian Teori}

\section{Definisi Kemampuan}

Dalam KBBI, kemampuan adalah kesanggupan, kecakapan, kekuatan kita berusaha dengan diri sendiri ${ }^{1}$. Sedangkan Anggiat dan Hadiati mendefinisikan kemampuan sebagai suatu dasar seseorang yang dengan sendirinya berkaitan dengan pelaksanaan pekerjaan secara efektif

\footnotetext{
${ }^{1}$ Kemendikbud. "Kamus Besar Bahasa Indonesia". kbbi.kemendikbud.go.id/entri/religious. Diakses tanggal 23 November 2019.
} 
atau sangat berhasil ${ }^{2}$. Berdasarkan pengertian di atas dapat disimpulkan bahwa kemampuan adalah kecakapan atau potensi seseorang individu untuk menguasai keahlian dalam melakukan atau mengerjakan bearagam tugas dalam suatu pekerjaan atau suatu penilaian atas tindakan seseorang.

\section{Operasi Hitung Pengurangan}

Pengertian operasi hitung pengurangan menurut Sri Sbarinah adalah salah satu konsep aritmatika yang harus dipelajari oleh siswa setelah penjumlahan ${ }^{3}$. Dan menurut Khafid dan Suyati, pengurangan adalah mengambil sebagian atau seluruhnya sehingga hasilnya menjadi semakin lebih sedikit ${ }^{4}$. Sedangkan menurut peneliti pengurangan adalah satu dari empat operasi dasar aritmatika, yang pada prinsipnya merupakan kebalikan dari operasi penjumlahan. Dalam pengoprasiannya pengurangan dilambangkan dengan simbol (-).

\section{Media Sempoa}

Sempoa adalah alat hitung sederhana yang pada mulanya terbuat dari kayu atau pada saat ini banyak yang terbuat dari plastik. Dalam bahasa Inggris, sempoa dikenal dengan nama abacus. Sempoa digunakan untuk melakukan operasi aritmatika seperti penjumlahan, pengurangan, perkalian, pembagian dan akar kuadrat. Pada saat ini, sempoa berbentuk persegi panjang dan dapat digunakan dengan mudah untuk menggeser manik-manik dengan menggunakan jari tangan. Pada sempoa terdapat beberapa deret tiang atau batang dimana manik-manik bergeser ke atas dan ke bawah. Setiap batang manik-manik mewakili bilangan yang berbeda-beda, yaitu dari bilangan satuan, puluhan, ratusan, dan seterusnya. ${ }^{5}$

\section{Metodologi}

Jenis penelitian ini adalah penelitian eksperimen semu (quasi eksperimen), karena peneliti tidak mampu mengontrol semua variabel yang mampu mempengaruhi. Pendekatan penelitian ini adalah pendekatan kuantitatif. Penelitian ini dilaksanakan di kelas II MI Islamiyah Mulyoagung Singgahan Tuban tahun pelajaran 2019/2020 yang berjumlah 34 siswa. Peneliti membagi sampel menjadi dua kelompok, yaitu kelompok eksperimen dan kelompok kontrol

\footnotetext{
${ }^{2}$ Anggiat dan Hadiati, Konsep dan Makna Pembelajaran. (Bandung: Alfabeta 2001). Hal. 34.

${ }^{3}$ Sri Sbarinah, Buku rujukan PGSD: Inovasi Pembelajaran Matematika SD (Jakarta: Depdiknas, 2006). Hal. 32.

${ }^{4}$ M. Khafid dan Suyati, Pelajaran Matematika Penekanan pada Berhitung untuk Sekolah Dasar Kelas 2 (Jakarta: Erlangga, 2009). Hal. 52.

${ }^{5}$ Sofan Kudlori dan Taufiq Hidayat, Makalah Training Guru Sempoa. (Surabaya: CV Sempoa Kreatif, 2014) Hal. 2.
} 
dengan cara random. Kelompok eksperimen adalah kelompok yang diberi pembelajaran dengan media sempoa, sedangkan kelompok kontrol adalah kelompok yang tidak diberi pembelajaran dengan media sempoa.

Data diperoleh dari kelompok eksperimen dan kelompok kontrol. Setiap siswa diberi pretest dan posttest. Pretest digunakan untuk mengetahui kemampuan awal setiap siswa. Sedangkan posttest digunakan untuk mengetahui kemampuan operasi hitung pengurangan siswa kelompok eksperimen setelah adanya treatment, serta untuk mengetahui apakah ada perbedaan nilai antara kelompok eksperimen atau kelompok yang mendapatkan treatment berupa pembelajaran dengan menggunakan media sempoa, dan kelompok kontrol atau kelompok yang tidak mendapatkan treatment pembelajaran menggunakan media sempoa.

Instrumen dan Teknik pengumpulan Data penelitian yang digunakan adalah:

\section{a. Instrumen Observasi}

Observasi atau yang disebut pula dengan pengamatan yang meliputi kegiatan pemuatan perhatian terhadap sesuatu objek dengan menggunakan seluruh alat indra ${ }^{6}$. Instrumen observasi dalam penelitian ini digunakan untuk mengobservasi guru matematika kelas II dalam pelaksanaan pembelajaran operasi hitung pengurangan menggunakan media sempoa. Waktu yang dilakukan selama observasi adalah (2x35 menit) perpertemuan, dan observasi ini dilakukan selama dua kali pertemuan. Untuk fokus yang diamati selama observasi adalah pelaksanaan pembelajaran operasi hitung pengurangan menggunakan media sempoa.

Tabel 1 Kisi-Kisi Instrumen Observasi Pelaksanaan Pembelajaran Operasi Hitung Pengurangan Menggunakan Media Sempoa

\begin{tabular}{|c|c|c|c|c|c|}
\hline \multirow{2}{*}{ No } & \multirow{2}{*}{ Aspek } & \multirow{2}{*}{ Indikator } & \multicolumn{2}{|c|}{ Keterlaksanaan } & \multirow{2}{*}{$\begin{array}{l}\text { Skor } \\
\text { Total }\end{array}$} \\
\hline & & & $\mathrm{Ya}$ & Tidak & \\
\hline \multirow[t]{4}{*}{1} & \multirow[t]{4}{*}{$\begin{array}{l}\text { Kegiatan inti } \\
\text { pembelajaran }\end{array}$} & $\begin{array}{l}\text { 1. Ketersediaan media sempoa } \\
\text { untuk guru dan siswa dalam } \\
\text { pembelajaran. }\end{array}$ & & & \\
\hline & & $\begin{array}{l}\text { 2. Guru menjelaskan sempoa } \\
\text { dan bagian-bagiannya }\end{array}$ & & & \\
\hline & & $\begin{array}{l}\text { 3. Guru menjelaskan tentang } \\
\text { rumus dasar pemakaian } \\
\text { sempoa untuk operasi hitung } \\
\text { pengurangan }\end{array}$ & & & \\
\hline & & $\begin{array}{ccc}\text { 4. Guru memberi } & \text { contoh } \\
\text { berhitung dengan } & \text { media }\end{array}$ & & & \\
\hline
\end{tabular}

\footnotetext{
${ }^{6}$ Suharsimi Arikunto, Prosedur Penelitian Suatu Pendekatan Praktik. (Jakarta: Rineka Cipta, 2014). Hal. 199.
} 


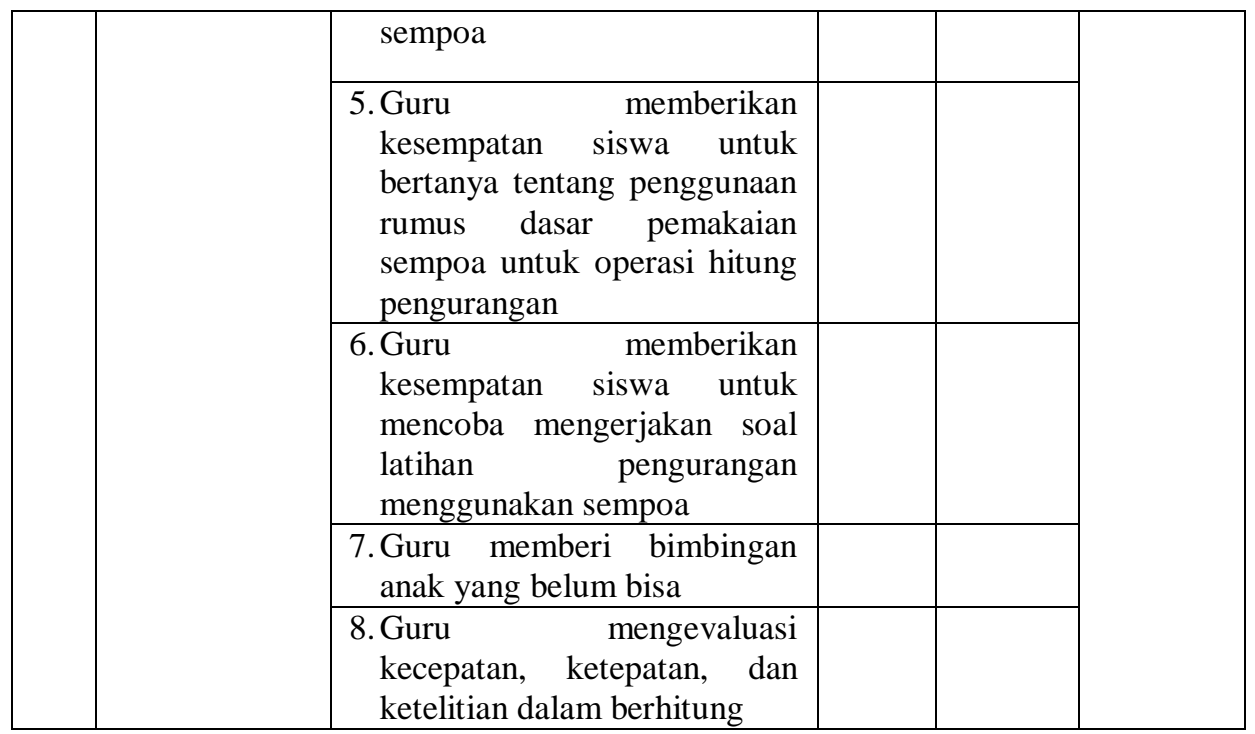

b. Instrumen Tes kemampuan operasi hitung pengurangan

Tes adalah sekumpulan pertanyaan maupun latihan serta alat lain yang digunakan untuk mengukur keterampilan, pengetahuan, intelegensi, kemampuan atau bakat yang dimiliki oleh individu atau kelompok ${ }^{7}$. Instrumen tes yang digunakan dalam penelitian ini adalah tes pretest dan posttest mengenai operasi hitung pengurangan. Teknik ini digunakan oleh peneliti untuk mengetahui kemampuan awal dan akhir setelah adanya media sempoa. Tes pretest digunakan untuk mengukur kemampuan awal siswa pada materi operasi hitung pengurangan, dan tes posttest digunakan untuk mengukur kemampuan kelompok eksperimen dan kelompok kontrol guna mengetahui apakah ada pengaruh atau perbedaan nilai antara kelompok yang menggunakan media sempoa (kelompok eksperimen) dan kelompok yang tidak menggunakan media sempoa (kelompok kontrol).

Selanjutnya, teknik analisis data yang digunakan pada penelitian ini adalah dengan menggunakan uji Independent sampel t-test, karena dua sampel ini tidak berhubungan atau dua kelompok yang anggotanya berbeda. Uji independent sample t-test adalah uji yang digunakan untuk mengetahui ada atau tidaknya perbedaan rata-rata antara dua kelompok sampel yang tidak berhubungan. ${ }^{8}$

Selanjutnya $t$ hitung dibandingkan dengan $\mathrm{t}$ tabel dengan $d k=n_{1}+n_{2}-2$. Dalam hal ini berlaku ketentuan bahwa:

\footnotetext{
${ }^{7}$ Ibid. 193.

${ }^{8}$ Sugiyono, Metode Penelitian Pendidikan (Pendekatan Kuantitatif, Kualitatif, dan R\&D). (Bandung: Alfabeta, 2015). Hal. 272.
} 
1. Apabila $t$ hitung lebih kecil atau sama dengan $t$ tabel, maka $H_{o}$ diterima dan $H_{a}$ ditolak. Yang berarti tidak ada pengaruh dalam penggunaan media sempoa terhadap kemampuan operasi hitung pengurangan siswa kelas II di MI Islamiyah Mulyoagung tahun pelajaran 2019/2020.

2. Dan apabila $t$ hitung lebih besar dari $t$ tabel, maka $H_{a}$ diterima dan $H_{o}$ ditolak. Yang berarti ada pengaruh dalam penggunaan media sempoa terhadap kemampuan operasi hitung pengurangan siswa kelas II di MI Islamiyah Mulyoagung tahun pelajaran 2019/2020.

\section{Hasil}

Dari hasil data observasi pada penelitian ini yaitu dalam melaksanakan kegiatan belajar mengajar (KBM) guru sudah melaksanakan semua indikator-indikator yang terdapat dalam lembar observasi sehimgga pembelajaran dapat terlaksana dengan kriteria sangat baik. Untuk lebih jelasnya hasil observasi peneliti sajikan di bawah ini:

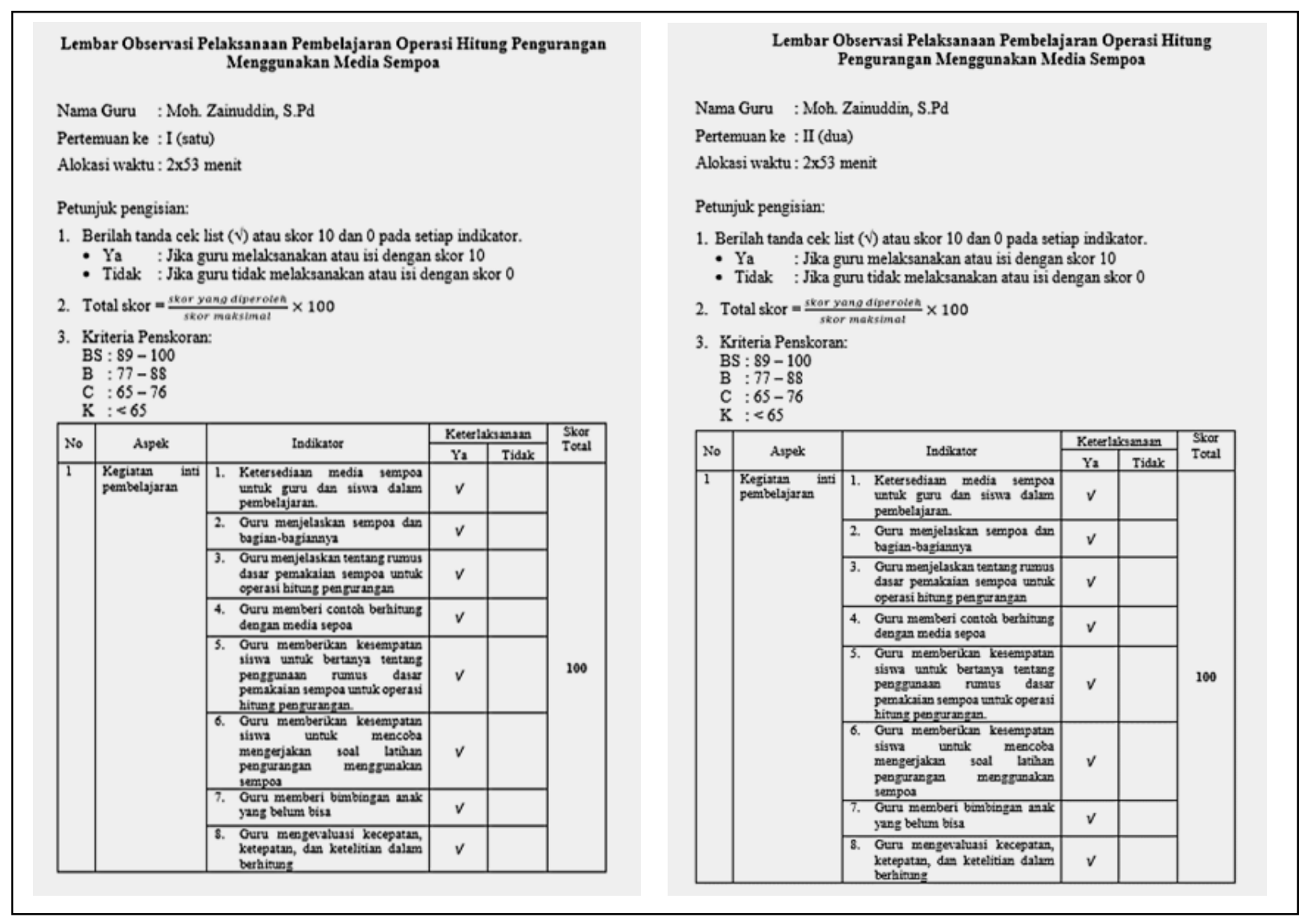


Sedangkan data hasil dari tes pretest dan posttest dapat dipaparkan sebagai berikut:

Hasil nilai pretest:

\begin{tabular}{|c|c|c|c|c|}
\hline \multirow{3}{*}{ No } & \multicolumn{4}{|c|}{ Nilai Pretest } \\
\hline & \multicolumn{2}{|l|}{ Kelompok Eksperimen } & \multicolumn{2}{|c|}{ Kelompok kontrol } \\
\hline & Nama & Nilai & Nama & Nilai \\
\hline 1 & Ahmad Khoirun Nizar & 70 & Abdallah Iqbal Maulana & 60 \\
\hline 2 & Ahmad Rosyihul Arzaq & 70 & Abdullah Wafi & 50 \\
\hline 3 & Ahmad 'Ubaidillah Al Hafidzi & 80 & Ahmad Ar-Rouf Muqtadir & 60 \\
\hline 4 & Anis Maymunah & 60 & Ahmad Hasanudin & 90 \\
\hline 5 & Ashalina Mahdiva Hafsa & 70 & Ayu Lestari & 70 \\
\hline 6 & \begin{tabular}{|l|} 
Erika Rahayu \\
\end{tabular} & 70 & Eka Nur Agustina & 50 \\
\hline 7 & Fira Dwi Nur Laili & 60 & $\begin{array}{l}\text { Hafiza Aprilia Putri } \\
\end{array}$ & 80 \\
\hline 8 & Imam Malik Budiono & 60 & Harirotun Nafísah & 60 \\
\hline 9 & Milandri Satria Putra Andalas & 60 & Inayatuzzahra & 60 \\
\hline 10 & Muhammad Ashfa Reza & 60 & M. Khoirur Roziqin & 70 \\
\hline 11 & Muhammad Afin Nuril Igdam & 80 & Muhammad Ibadus Sholihin & 70 \\
\hline 12 & Muhammad Ammar Atana & 90 & Muhammad Khoirur Nizam & 70 \\
\hline 13 & Nadiyah Maula & 80 & Muhammad Zainul Muttagin & 80 \\
\hline 14 & Najma Tsuroyya Tartakiza & 70 & Rabiya Putri Ramadlani & 80 \\
\hline 15 & Nurul Aulia Zhafira Ulfa & 60 & Rendy Firnanda Ramadhan & 70 \\
\hline 16 & Rania Nabila & 70 & Rohmatul Lailiyyah & 70 \\
\hline 17 & \begin{tabular}{|l} 
Sinta Nur Aini \\
\end{tabular} & 60 & Roufatun Khasanah & 70 \\
\hline $\mathbf{N}$ & 17 & 1170 & 17 & 1160 \\
\hline
\end{tabular}

Hasil nilai posttest:

\begin{tabular}{|c|c|c|c|c|}
\hline \multirow{3}{*}{ No } & \multicolumn{4}{|c|}{ Nilai Posttest } \\
\hline & \multicolumn{2}{|l|}{ Kelompok Eksperimen } & \multicolumn{2}{|c|}{ Kelompok Kontrol } \\
\hline & Nama & Nilai & Nama & Nilai \\
\hline 1 & Ahmad Khoirun Nizar & 80 & Abdallah Igbal Maulana & 70 \\
\hline 2 & Ahmad Rosyihul Arzag & 80 & Abdullah Wafi & 60 \\
\hline 3 & Ahmad 'Ubaidillah Al Hafidzi & 90 & Ahmad Ar-Rouf Muqtadir & 60 \\
\hline 4 & Anis Maymunah & 70 & Ahmad Hasanudin & 90 \\
\hline 5 & Ashalina Mahdiya Hafsa & 80 & Ayu Lestari & 70 \\
\hline 6 & Erika Rahayu & 80 & Eka Nur Agustina & 50 \\
\hline 7 & Fira Dwi Nur Laili & 70 & Hafiza Aprilia Putri & 70 \\
\hline 8 & Imam Malik Budiono & 80 & Harirotun Nafisah & 60 \\
\hline 9 & Milandri Satria Putra Andalas & 70 & Inayatuzzahra & 70 \\
\hline 10 & Muhammad Ashfa Reza & 70 & M. Khoirur Roziqin & 80 \\
\hline 11 & Muhammad Afin Nuril Iqdam & 100 & Muhammad Ibadus Sholihin & 70 \\
\hline 12 & Muhammad Ammar Atana & 100 & Muhammad Khoirur Nizam & 60 \\
\hline 13 & Nadiyah Maula & 90 & Muhammad Zainul Muttaqin & 80 \\
\hline 14 & Najma Tsuroyya Tartakiza & 80 & Rabiya Putri Ramadlani & 70 \\
\hline 15 & Nurul Aulia Zhafira Ulfa & 80 & Rendy Firnanda Ramadhan & 80 \\
\hline 16 & Rania Nabila & 90 & Rohmatul Lailiyyah & 70 \\
\hline 17 & Sinta Nur Aini & 80 & Roufatun Khasanah & 60 \\
\hline $\mathbf{N}$ & 17 & 1390 & 17 & 1170 \\
\hline
\end{tabular}

Berdasarkan tabel di atas dapat dilihat bahwa pada hasil nilai pretest hampir tidak ada perbedaan data hasil yang diperoleh kelompok eksperimen dan kelompok kontrol. Sedangkan pada hasil tes posttest dapat dilihat bahwa setelah adanya treatment terhadap kelompok eksperimen mengalami peningkatan dari pada kelompok yang tidak diberi treatment (kelompok kontrol). Untuk mengetahui pengaruh media sempoa terhadap kemampuan operasi hitung pengurangan digunakan rumus uji $\mathrm{t}$ independent sample $t$ test dengan rumus poolled varians. Hasil perhitungan uji $t$ independent sample $t$ test adalah sebagai berikut: 


$$
\begin{aligned}
t_{\text {hitung }} & =\frac{\bar{X}_{1}-\bar{X}_{2}}{\sqrt{\frac{\left(n_{1}-1\right) s_{1}^{2}+\left(n_{2}-1\right) s_{2}^{2}}{n_{1}+n_{2}-2}\left(\frac{1}{n_{1}}+\frac{1}{n_{2}}\right)}} \\
& =\frac{81,76-68,82}{\sqrt{\frac{(17-1) 9,51^{2}+(17-1) 9,93^{2}}{17+17-2}\left(\frac{1}{17}+\frac{1}{17}\right)}} \\
& =\frac{12,94}{\sqrt{\frac{(16 \times 90,44)+(16 \times 98,60)}{34-2}\left(\frac{2}{17}\right)}} \\
& =\frac{12,94}{\sqrt{\frac{1447,04+1577,6}{32}\left(\frac{2}{17}\right)}} \\
& =\frac{12,94}{\sqrt{\frac{3024,64}{32}\left(\frac{2}{17}\right)}} \\
& =\frac{12,94}{\sqrt{94,52\left(\frac{2}{17}\right)}} \\
& =\frac{12,94}{\sqrt{11,12}=\frac{12,94}{3,33}} \\
& =3,88
\end{aligned}
$$

Hasil perhitungan uji t berdasarkan analisis uji t independent sample t test dengan rumus poolled varians yang telah dilakukan, didapatkan $t_{\text {hitung }}$ sebesar 3,88. Berdasarkan hasil tersebut dapat dijelaskan secara detail bahwa $t_{\text {hitung }}>t_{\text {tabel }}$ pada taraf signifikan 5\% $(3,88>1,693)$. Berdasarkan hasil di atas, maka $\mathrm{H}_{\mathrm{a}}$ diterima dan $\mathrm{H}_{0}$ ditolak sehingga dapat disimpulkan bahwa ada pengaruh media sempoa terhadap kemampuan operasi hitung pengurangan siswa kelas II di MI Islamiyah Mulyoagung Singgahan Tuban tahun pelajaran 2019/2020.

\section{Kesimpulan}

Berdasarkan hasil analisis data penelitian yang telah dipaparkan sebelumnya serta mengacu pada rumusan masalah yang telah diuraikan pada bagian sebelumnya, dapat disimpulkan bahwa ada pengaruh yang signifikan dalam penggunan media sempoa terhahap 
kemampuan operasi hitung pengurangan siswa di kelas II MI Islamiyah Mulyoagung tahun pelajaran 2019/2020 dengan hasil pengujian hipotesis diperoleh $t_{\text {hitug }}$ sebesar 3,882 $>t_{\text {tabel }}$ yaitu 1,693 pada taraf signifikan $5 \%$.

\section{Daftar Referensi}

Anggiat M, Sinaga dan Sri Hadiati. (2001). Konsep dan Makna Pembelajaran. Bandung: Alfabeta.

Arikunto, Suharsimi. (2014). Prosedur Penelitian Suatu Pendekatan Praktik. Jakarta: Rineka Cipta.

Kamus Besar Bahasa Indonesia (KBBI). (online). Tersedia di kbbi.kemendikbud.go.id/entri/religious. Diakses 23 November 2019.

Khudlori, Sofan dan Taufiq Hidayat (2014). Makalah Training Guru Sempoa. Surabaya: CV Sempoa Kreatif.

Sabarinah, Sri. (2006). Buku rujukan PGSD: Inovasi Pembelajaran Matematika SD. Jakarta: Depdiknas

Sugiyono. (2015). Metode Penelitian Pendidikan (Pendekatan Kuantitatif, Kualitatif, dan R\&D). Bandung: Alfabeta.

Suyati dan M. Khafid. (2009). Pelajaran Matematika Penekanan pada Berhitung untuk Sekolah Dasar Kelas 2. Jakarta: Erlangga. 